\title{
Display of the $\beta$-effect in the Black Sea Two-Layer Model
}

\author{
A.A. Pavlushin, N.B. Shapiro, E.N. Mikhailova
}

Marine Hydrophysical Institute, Russian Academy of Sciences, Sevastopol, Russian Federation e-mail: pavlushin@mhi-ras.ru

\begin{abstract}
The research is a continuation of a series of numerical experiments on modeling formation of wind currents and eddies in the Black Sea within the framework of a two-layer eddy-resolving model. The main attention is focused on studying the $\beta$-effect role. The stationary cyclonic wind is used as an external forcing and the bottom topography is not considered. It is shown that at the $\beta$-effect being taken into account, the Rossby waves propagating from east to west are observed both during the currents' formation and at the statistical equilibrium mode when the mesoscale eddies are formed. In the integral flows' field the waves are visually manifested in a form of the alternate large-scale cyclonic gyres and zones in which the meso-scale anti-cyclones are formed. This spatial pattern constantly propagates to the west that differs from the results of calculations using the constant Coriolis parameter when the spatially alternate cyclonic and anti-cyclonic vortices are formed, but hold a quasi-stationary position. The waves with the parameters of the Rossby wave first barotropic mode for the closed basin are most clearly pronounced. Interaction of the Rossby waves with largescale circulation results in intensification of the of the currents' hydrodynamic instability and in formation of the mesoscale eddies. Significant decrease of kinetic and available potential energy as compared to the values obtained at the constant Coriolis parameter is also a consequence of the eddy formation intensification.
\end{abstract}

Keywords: the Black Sea, eddy-resolving model, numerical experiment, $\beta$-effect, Rossby waves.

DOI: $10.22449 / 1573-160 X-2016-5-3-23$

(C) 2016, A.A. Pavlushin, N.B. Shapiro, E.N. Mikhailova

(C) 2016, Physical Oceanography

Introduction. To investigate the effect of various factors (internal and external) on the formation and evolution of the hydrophysical fields in the Black Sea, a series of targeted numerical experiments with eddy-resolving two-layer isopycnic model was carried out [1,2]. The model is based on a system of primitive equations in the Boussinesq, hydrostatic and $\beta$-plane approximations. The sea comprising of two layers with the upper layer density $\rho_{1}=$ const and the lower layer one $\rho_{2}=$ const. The layers are not mixed with each other. The friction between the layers can be taken into account in the model. The tangential wind stress $\tau$ is set on the sea surface. The energy sink is carried out at the expense of the bottom friction and horizontal turbulent viscosity.

The equations of motion and continuity, vertically integrated within each layer, have the following form

$$
\begin{aligned}
\left(U_{1}\right)_{t}+\left(u_{1} U_{1}\right)_{x}+ & \left(v_{1} U_{1}\right)_{y}-f V_{1}=g h_{1} \zeta_{x}+\tau^{x}-R_{a}^{x}+A_{l} \nabla\left(h_{1} \nabla u_{1}\right), \\
& \left(V_{1}\right)_{t}+\left(u_{1} V_{1}\right)_{x}+\left(v_{1} V_{1}\right)_{y}+f U_{1}= \\
= & g h_{1} \zeta_{y}+\tau^{y}-R_{a}^{y}+A_{l} \nabla\left(h_{1} \nabla v_{1}\right),
\end{aligned}
$$




$$
\begin{gathered}
\left(U_{2}\right)_{t}+\left(u_{2} U_{2}\right)_{x}+\left(v_{2} U_{2}\right)_{y}-f V_{2}=g h_{2} \zeta_{x}+g^{\prime} h_{2}\left(h_{1}\right)_{x}+R_{a}^{x}-R_{b}^{x}+A_{l} \nabla\left(h_{2} \nabla u_{2}\right), \\
\left(V_{2}\right)_{t}+\left(u_{2} V_{2}\right)_{x}+\left(v_{2} V_{2}\right)_{y}+f U_{2}= \\
=g h_{2} \zeta_{y}+g^{\prime} h_{2}\left(h_{1}\right)_{y}+R_{a}^{y}-R_{b}^{y}+A_{l} \nabla\left(h_{2} \nabla v_{2}\right), \\
\left(h_{1}\right)_{t}+\left(U_{1}\right)_{x}+\left(V_{1}\right)_{y}=0, \\
\left(h_{2}\right)_{t}+\left(U_{2}\right)_{x}+\left(V_{2}\right)_{y}=0,
\end{gathered}
$$

where indices 1 and 2 denote the upper and lower layer correspondingly; the lower indices $x, y$ and $t$ designate differentiation; $u_{i}, v_{i}$ are the $i$-layer horizontal components of the current velocity; $h_{1}, h_{2}$ are the layer thickness; $U_{1}=u_{i} h_{i}$, $V_{1}=v_{i} h_{i}$ are the flow components; $\zeta$ is the sea level; $R_{a}^{X}=r_{a}\left(u_{1}-u_{2}\right)$, $R_{a}^{y}=r_{a}\left(v_{1}-v_{2}\right)$ are the components of the friction force between the layers; $R_{b}^{X}=r_{b} u_{2}, R_{b}^{y}=r_{b} v_{2}$ are the bottom friction force components; $r_{a}, r_{b}$ are the constant coefficients; $f=f_{0}+\beta y$ is the Coriolis parameter, $f_{0}=10^{-4} 1 / \mathrm{s}$, $\beta=2 \cdot 10^{-13} 1 /(\mathrm{cm} \cdot \mathrm{s}) ; \quad g=980 \mathrm{~g} \cdot \mathrm{cm} / \mathrm{s}^{2} \quad$ is the free fall acceleration; $g^{\prime}=g\left(\rho_{2}-\rho_{1}\right) / \rho_{2} ; \tau^{x}, \tau^{y}$ are the tangential wind stress components; $A_{l}$ is the horizontal eddy viscosity coefficient.

The integral continuity equation in the rigid lid approximation terminates the equations. It permits to introduce the stream function $\psi$ for the total flows:

$$
U_{1}+U_{2}=-\psi_{y}, \quad V_{1}+V_{2}=\psi_{x} .
$$

At the side basin boundaries the no-slip conditions are set. River runoff into the sea and water exchange through the straits are not taken into account. Initially, the water is at rest, the interface layer and the sea surface are horizontal.

In the finite-difference model representation a time two-layer numerical scheme is applied. It is based on the $B$-grid box method (in the terminology of Arakawa), the implicit approximation of the Coriolis force and friction forces on the section and the bottom surface. Advective members in the equations of continuity are approximated by the first accuracy order (directed differences) scheme and in the equations of motion - by the second accuracy order scheme of the (Lax - Wendroff).

The first stage of the works involved the study of the wind circulation formation mechanisms, due to the fact that the wind is a major factor in determining the Black Sea seasonal and interannual variability. Taking into account the characteristics and specifics of the model applied, it is possible to identify the important factors that influence the dynamics of currents, such as the wind spatio-temporal variability, the horizontal turbulent viscosity, the bottom friction force, the friction force between the layers, the basin shape, especially the coastline, $\beta$-effect, the bottom topography. 
The paper [1] presents the analysis of the results of experiments with different coefficients of horizontal turbulent viscosity $A_{l}$ and bottom friction $r_{b}$ at the constant Coriolis parameter $f_{0}=10^{-4} 1 / \mathrm{s}$, corresponding to the Black Sea latitude. It is shown that satisfactory results in the model are obtained using the coefficients $A_{l} \sim 10^{5} \mathrm{~cm}^{2} / \mathrm{s}$ and $r_{b}$ in the range of $0.01-0.1 \mathrm{~cm} / \mathrm{s}$. Under these parameters in the basin alongside with the stable quasi-stationary cyclonic gyres the mesoscale anticyclonic eddies associated with the hydrodynamic instabilities of currents sporadically appear.

In the paper [2] the effect of the basin shape on circulation was studied. The results of calculations of current fields in basins with different configurations in the absence of $\beta$-effect were analyzed. In the stretched basins, provided the bottom friction is quite weak, the large-scale circulation is divided into individual cyclonic eddies, even without the protruding coastline elements available. The number of these eddies depends on the ratio of the length of the basin to its width.

In the papers $[1,2]$ the energy inflow in the sea under the stationary wind $\vec{\tau}(t)=$ const is also shown to be regulated by the oscillatory process [3] associated with changes in the work of the tangential wind stress $W_{\tau}=|\vec{\tau}| \cdot\left|\vec{u}_{1}\right| \cdot \cos (\alpha)$. This is due to the transformation of the surface current field $\vec{u}_{1}$ by mesoscale eddies generated by hydrodynamic (barotropic and/or baroclinic) large-scale circulation instability. The period of oscillation in the $\beta$-effect absence is mainly determined by the lifetime of mesoscale eddies.

In the present article the research of the $\beta$-effect role on the formation of winddriven circulation in the Black Sea is carried out. According to the theory [4 -6] latitude change of the Coriolis parameter leads to appearance of the planetary Rossby waves, which can have a very wide range of manifestations depending on various conditions. The Black Sea specificity is that it is almost a closed basin. Its size is less than the barotropic (external) Rossby deformation radius, but more than baroclinic (internal) deformation radius.

There are a number of works that are directly or indirectly related to the modeling and description of processes in the Black Sea, connected with the manifestation of planetary waves [7 - 14]. First of all, the works of E. Stanev, N. Rachev $[7,8]$ should be paid attention to. There the analysis of the numerical simulation of wind circulation in the Black Sea applying the level eddy-resolving Bryan - Cox model is described. The movement in the sea as well as in our case was excited by stationary wind. As a result of computations performed in the Black Sea long-term fluctuations were obtained. They were described as barotropic Rossby waves generated in a closed basin, whose dimensions are smaller than the outer radius of deformation. According to the authors of [8], the Rossby waves are the dominant form of wave motion in the Black Sea and the variability of the circulation associated with planetary modes can be compared in some cases with the variability caused by baroclinic instability.

Similar results were obtained in the paper [9], dedicated to the modeling of wind circulation in the Black Sea applying quasi-geostrophic model. During the numerical integration under the stationary wind influence a problem solution came 
out on a quasi-periodic mode with the oscillations in the total flow fields with periods of 43 and 83 days. According to opinion of the authors, the first of these periods is associated with the manifestation of baroclinic instability of the main current, and the second one can be caused by manifestation of barotropic Rossby waves.

In [10] based on the processing of satellite observations of the Black Sea level changes the long-period oscillations propagating in the western direction were monitored. The authors explain this process by radiation of the baroclinic Rossby waves, caused by seasonal fluctuations of the wind vorticity from, the eastern coast of the sea.

In [11] based on the analysis of hydrophysical and morphometric characteristics of the Black Sea, the conclusion about the possible existence of the Rossby waves in the basin with periods of $80-200$ days and phase velocities of $2-8 \mathrm{~cm} / \mathrm{s}$ is drawn.

As the observational data indicating the presence of planetary waves in the Black Sea basin, the works $[12,13]$ can also be mentioned. They describe the anticyclonic mesoscale eddies generated in the Black Sea during summer. Monitoring of the eddies showed that during the observation period, they had a velocity component of $\sim 2 \mathrm{~km} /$ day, directed to the west, which may indicate their relation to the Rossby waves.

Generally, the features of the appearance and propagation of planetary waves in the Black Sea have not been studied enough.

Description of the experiments. As it was previously mentioned, the experiments considered in the present paper, are devoted to $\beta$-effect and its effect on the formation of wind circulation in the Black Sea. The experiments do not take into account the bottom topography and friction between the layers. $\tau$ wind power is set stationary at a constant cyclonic vorticity $0,5 \cdot 10^{-7} \mathrm{~N} / \mathrm{m}^{3}$. The sea depth is set equal to $H=2200 \mathrm{~m}$. The upper layer initial thickness is $h_{0}=175 \mathrm{~m}$, the Coriolis parameter on the southern boundary is $\beta=2 \cdot 10^{-13} \mathrm{~s}^{-1} \mathrm{~cm}^{-1}$, the Rossby parameter is $\beta=2 \cdot 10^{-13} \mathrm{~s}^{-1} \mathrm{~cm}^{-1}$, horizontal eddy viscosity coefficient is $A_{l}=10^{5} \mathrm{~cm}^{2} \mathrm{~s}^{-1}$.

In previous studies $[1,2]$ it was shown that the results of solving the problem under the constant Coriolis parameter are very sensitive to the value of bottom friction, while $r_{b}$ ratio variation range is quite wide. Therefore, computations with different values of the $r_{b}$ coefficient were carried out.

For the convenience of description, in the present paper we introduced the following alphanumeric designations of the experiments. In the numerical experiments, indicated by the letter $\mathrm{B}, \beta>0$, experiments with $\beta=0$ are indicated by the letter $\mathrm{A}$. The paper discusses the results of six experiments: B1, B2, B3 and $\mathrm{A} 1, \mathrm{~A} 2, \mathrm{~A} 3$. In addition to $\beta$-parameter, the difference between them is in the use of different values of the $r_{b}$ bottom friction coefficient: in B1, A1, B3, A3 experiments $r_{b}=0.01 \mathrm{~cm} / \mathrm{s}$; B2, A2 ones $-r_{b}=0.1 \mathrm{~cm} / \mathrm{s}$.

Furthermore, in B3 and A3 experiments the model basin shape ("sausage"type), the same as in F1 experiment in [2], is used except the actual Black Sea 
configuration. This makes it possible to demonstrate the influence of the effect of the basin configuration and coastline features on the formation of currents, eddies and Rossbi waves.

The computations were performed on a $3 \times 3 \mathrm{~km}$ square grid with a time step of $\Delta t=3 \mathrm{~min}$. The use of a high spatial resolution compared to the previous works [1, 2], which applied a $4 \times 3.5 \mathrm{~km}$ grid and time step of $\Delta t=6 \mathrm{~min}$., permitted to obtain the smaller eddies with an increase in their quantity in the study area

Duration of the computations in each experiment was not less than 10 years. The experiment was stopped after the decision came out on a statistically equilibrium mode [2], in which the averaged time characteristics of the model has changed little over time.

Results of the numerical experiments. The performed computations resulted in obtaining instantaneous and averaged over time fields of the upper layer thickness $h_{1}$, the sea level $\zeta$, currents in the upper and lower layer $\vec{u}_{1}, \vec{u}_{2}$ and integrated stream function $\psi$.

In addition, graphs of the time changes of area averaged values were constructed. These values were the kinetic energy of the upper and lower layer $K E_{1}$ $K E_{2}$, available potential energy $D P E$ and tangential wind stress work $W_{\tau}$ calculated according to the following formulas

$$
\begin{gathered}
K E_{1}=\left\langle\rho_{1} h_{1}\left(u_{1}^{2}+v_{1}^{2}\right) / 2\right\rangle, K E_{2}=\left\langle\rho_{2} h_{2}\left(u_{2}^{2}+v_{2}^{2}\right) / 2\right\rangle, \\
D P E=\left\langle\rho_{1} g^{\prime}\left(h_{1}-h_{0}\right)^{2} / 2\right\rangle, W_{\tau}=\left\langle\rho_{1}\left(u_{1} \tau^{x}+v_{1} \tau^{y}\right)\right\rangle,
\end{gathered}
$$

where $h_{1}, h_{2}$ are the upper and lower layer thickness; $u_{1}, v_{1}, u_{2}$ and $v_{2}$ horizontal components of the current velocities in the respective layers; $g^{\prime}=g\left(\rho_{2}-\rho_{1}\right) / \rho_{2}=$ $3,2 \mathrm{~cm} / \mathrm{s}^{2} ; \tau_{x}, \tau_{y}$ are the tangential wind stress horizontal components; the angle brackets denote averaging over the area.

Results of the computations obtained under $\beta>0$ were compared with results of the experiments where $\beta$-parameter was assumed to be zero.

Fig. 1 shows the instantaneous spatial distributions of the features in B1 and A1 experiments. A1 experiment $(\beta=0)$ is characterized by the presence of all the fields in the two large-scale cyclonic gyres (Fig. 1, $a-e$ ). One cycle is located in the western part of the sea, the other - in the east one. These sub-basin cyclones define large-scale circulation in the basin. Between the cyclones and the coast and between mesoscale cyclones anticyclonic eddies occasionally appear. They are clearly visible in the $h 1, \zeta$ and $\vec{u}_{1}$ fields (Fig. $1, f-h$ ). Their lifetime is about 50 days. 
There are clearly distinguished two cyclonic eddies averaged over several in the fields $h_{1}$ and $\psi$ (Fig. 2, $a, b$ ). They were also observed in the instantaneous distributions. This testifies their stationary nature. With regard to mesoscale anticyclonic eddies, due to their non-stationarity in time and space, they are weakly manifested in the averaged field $\psi$ and do not appear at all in the field $h_{1}$.
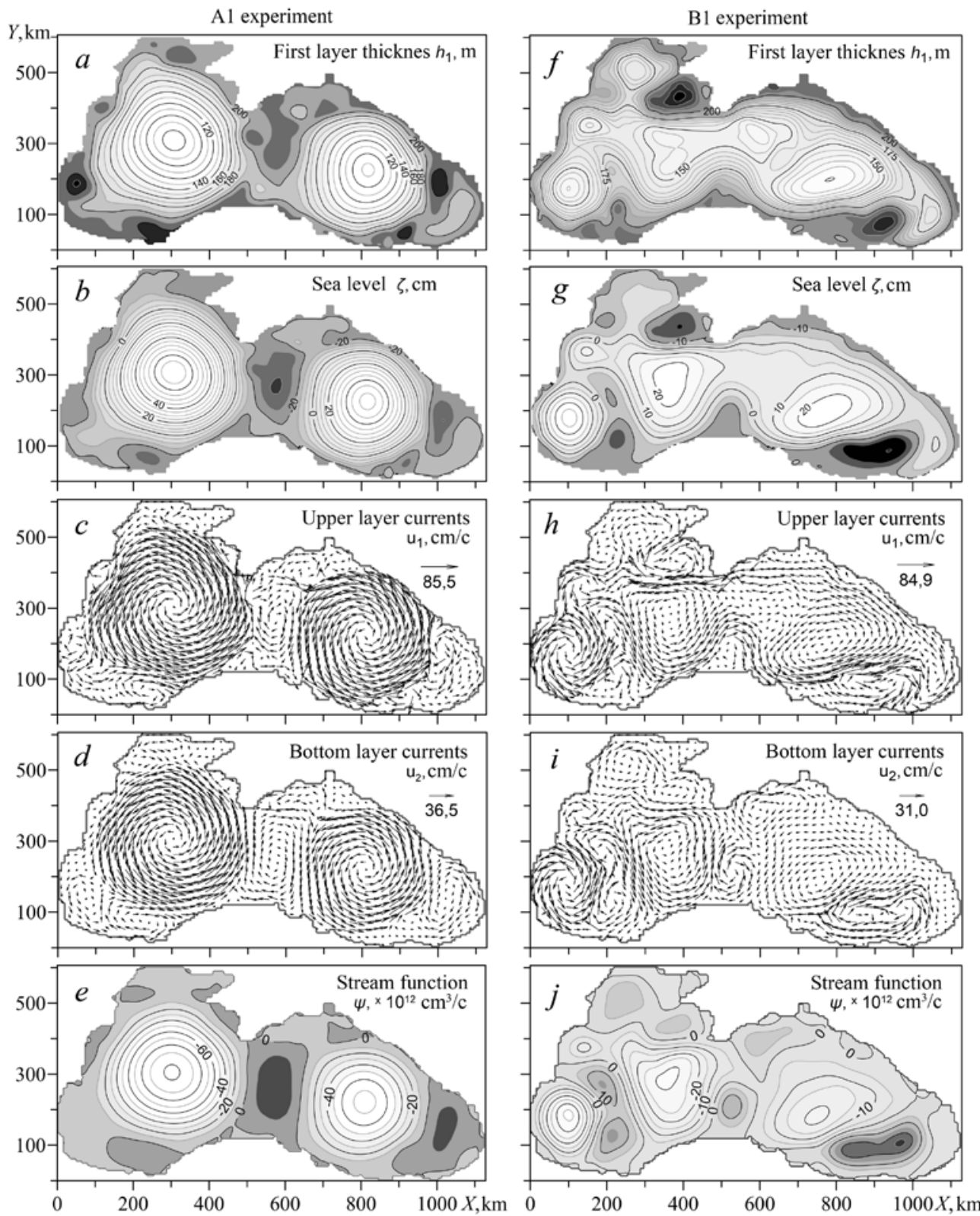

Fig. 1. The instantaneous spatial distributions of the features in the experiment A1 (left) и B1 (right) 

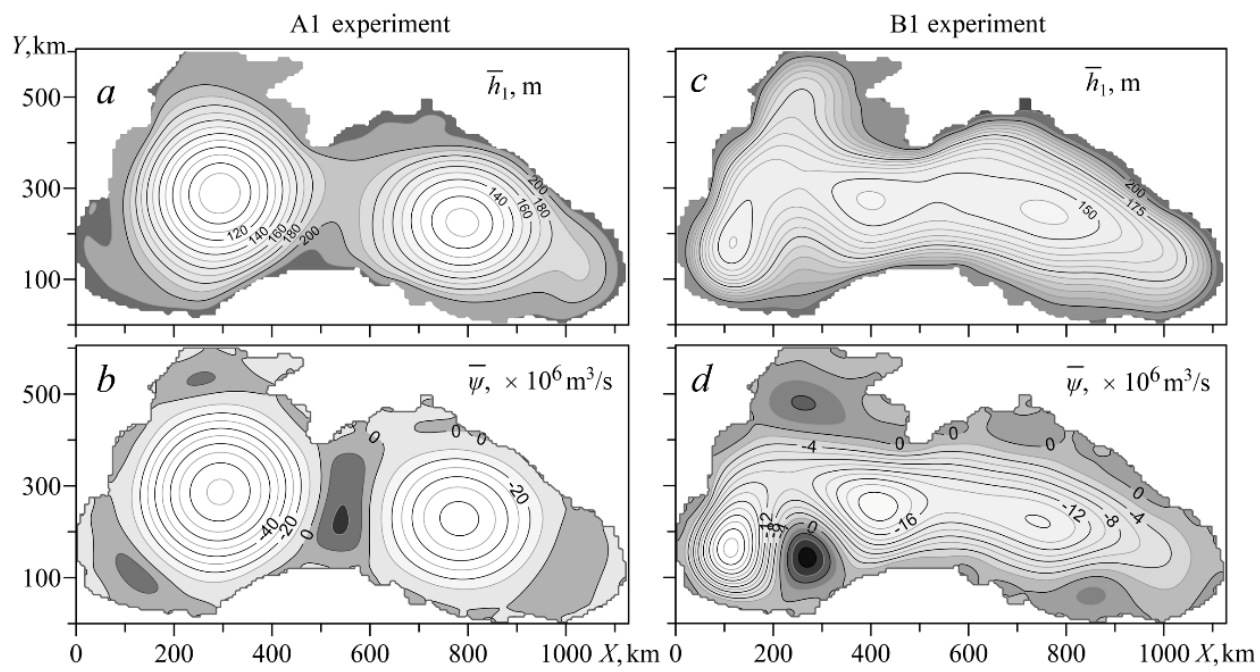

Fig. 2. Average distributions $h_{1}$ and $\psi$ in the experiments A1 (left) and B1 (right)

In the experiment (B1) with $\beta$-effect taken into account the large-scale cyclones in the sea central part are also found in the instantaneous distributions $h_{1}$, $\zeta$ and $\vec{u}_{1}$ (Fig. 1, $a-c$ ) (B1), but, unlike A1 experiment, they are weaker, and their number is more than two. Therefore, we can rather speak of the presence of a large-scale cyclonic gyre with several peaks in the central part of the given basin. Mesoscale anticyclonic eddies are observed along the coast.

The single cyclonic and anticyclonic eddies are more distinguished in the fields $\psi$ and $\vec{u}_{2}$ in $\mathrm{B} 1$ experiment than in the upper layer.

Eddy formations, available in instantaneous fields, are constantly moving. It leads appearance of a vast cyclonic area $\mathrm{t}$ in the medium fields $h_{1}$ and $\psi$ in the central part of the basin (Fig. 2. $c, d$ ). As a consequence of the intensification of western currents, there is a slight thickening of the isolines $h_{1}$ and $\psi$ near the western coast.

In both experiments considered the qualitative coincidence of current fields in the upper and lower layers, indicating that the process barotropization is noteworthy. The direction of currents in the upper and lower layers is substantially the same. The velocity of currents in the lower layer is about $40 \%$ of the one in the upper layer.

Integrated stream function $\psi$, which characterizes the barotropic currents, correlates well with the field $\vec{u}_{2}$, and the isolines $h_{1}$ are close to the current lines $\vec{u}_{1}$ and the isolines $\zeta$. This peculiarity in the spatial distributions of the features permits to apply the field $h 1$ to visualize the circulation in the upper layer and $\psi-$ in the lower one. 


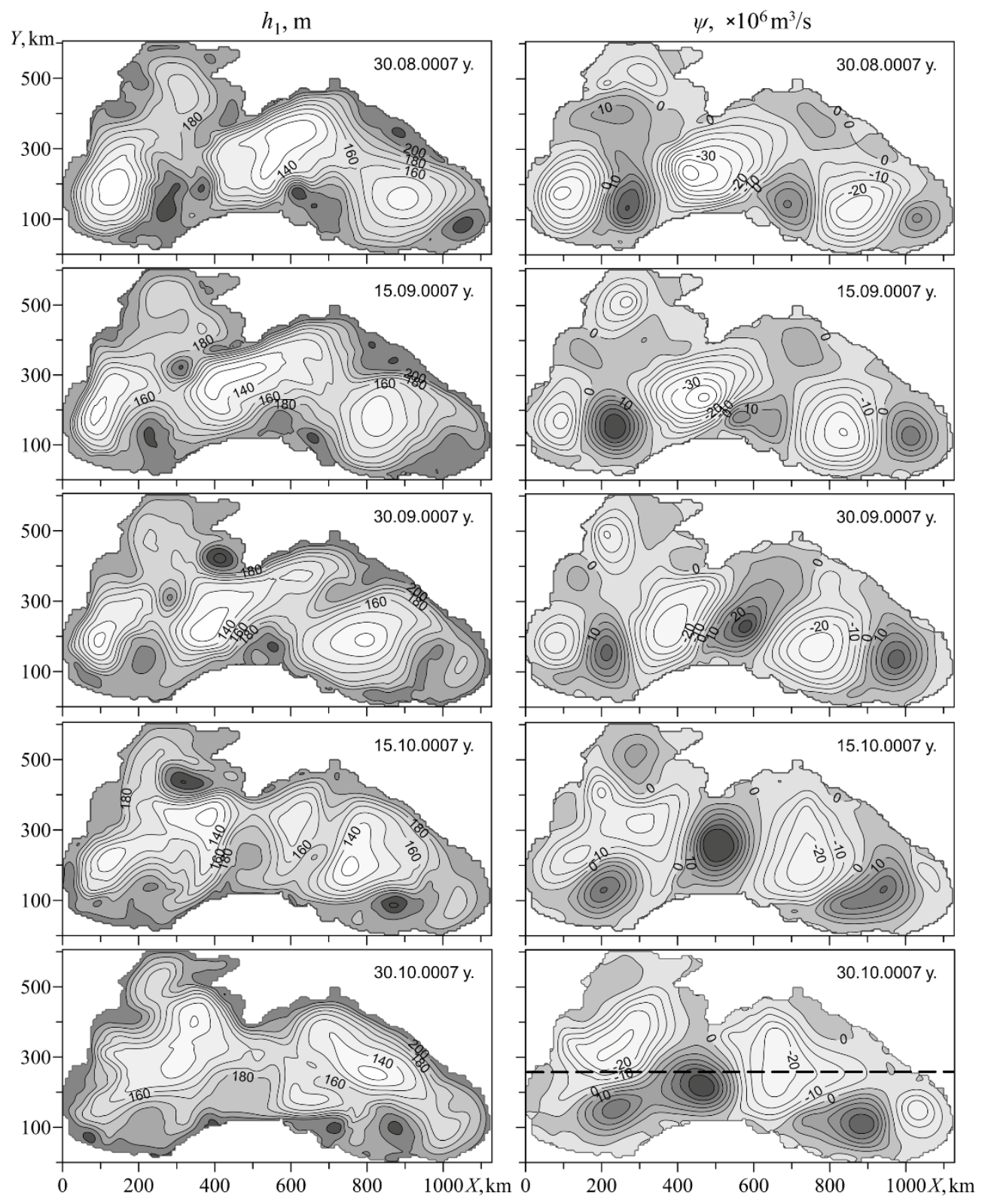

Fig. 3. Consequent fields $h_{1}$ (left) and $\psi$ (right) with 15 day period in B1 experiment. The dotted line represents the section $Y=270 \mathrm{~km}$

As it has already been mentioned, the eddy formations occurring under $\beta>0$, do not have a stationary position. If the sequence of instantaneous fields $h_{1}$ and $\psi$, created for B1 experiment, is considered (Fig. 3), the movement of eddy formation has mainly the western direction, which is not observed in A1 experiment.

In graphs $h_{1}$ and $\psi$ (Fig. 4), plotted for the latitudinal section, going through the central sea part along the line $Y=270 \mathrm{~km}$, the waves moving at $8 \mathrm{~cm} / \mathrm{s}$ velocity with $80-100$ day period in the western direction, can bee seen. In field $\psi$ these 
waves are better manifested than in $h_{1}$ one, as in the upper layer the currents and mesoscale eddies associated with baroclinic instability are superposed on them.
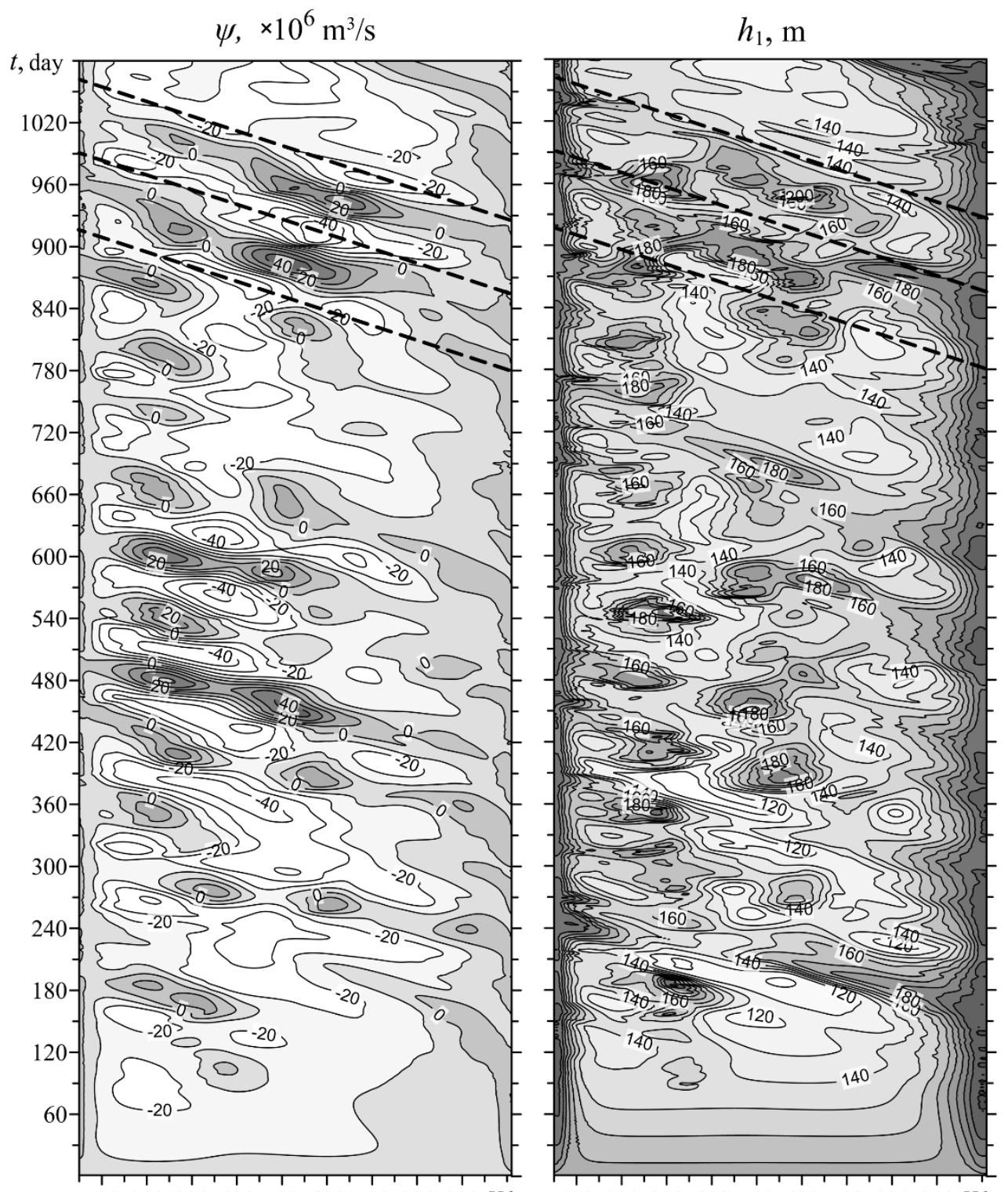

$100200300400500600700800900 X, \mathrm{~km} 100200300400500600700800900 X, \mathrm{~km}$

Fig. 4. Time graphs $\psi$ (left) and $h_{1}$ (right) on the section $Y=270 \mathrm{~km}$ in B1 experiment

The $\beta$-effect role is also manifested in the behavior of energy. Fig. $5, a, b, c, d$ show the graphs of the area averaged $K E_{1}, K E_{2}, D P E, W_{\tau}$, calculated for $\mathrm{B} 1$ and $\mathrm{A} 1$ experiments. 

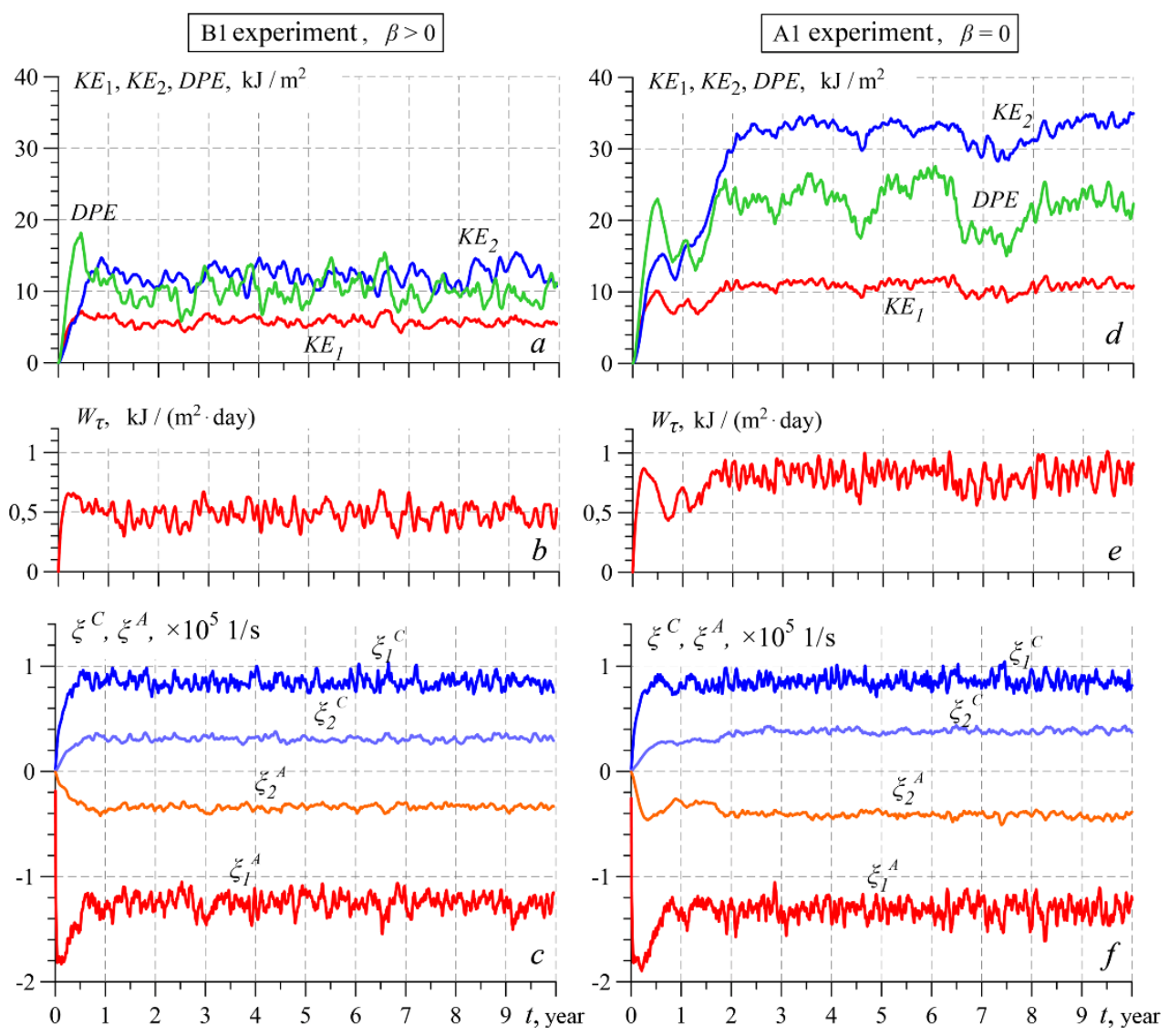

Fig. 5. Energy graphs of $K E_{1}, K E_{2}, D P E$ in $\mathrm{B} 1(a)$ and $\mathrm{A} 1(d)$ experiments; the tangential wind stress work $W_{\tau}$ in B1 (b) and A1 (e) experiments; mean vorticity B1 (c) and A1 (f)

Fig. $5 a, d$, show the solution reaches a statistically equilibrium mode, the characteristics change within the relatively limited certain mean values in the both experiments.

In $\mathrm{B} 1$ experiment under $\beta>0$ the $K E_{1}, K E_{2}$ and $D P E$ energy values resulted significantly smaller than in A1 experiment. The work $W_{\tau}$, which provides the energy inflow in the sea, also appeared smaller. As $W_{\tau}$ is determined by oscillatory process, depending on the stability of currents in the upper layer, it can be assumed that the $\beta$-effect influences the currents, making them more instable.

It can be seen if we calculate separately the average area values of cyclonic and anticyclonic relative vorticity in the different layers of the model. It is necessary to sum over areas cyclonic and anticyclonic vorticity values in each layer separately and divide by the corresponding areas. The resulting mean values for cyclonic and anticyclonic vorticity will be denoted as $\xi_{1}^{C}, \xi_{2}^{C} \quad \xi_{1}^{A}$ and $\xi_{2}^{A}$ :

$$
\xi_{i}^{C}=\frac{1}{S_{i}^{C}} \iint_{C_{i}}\left(\frac{\partial v_{i}}{\partial x}-\frac{\partial u_{i}}{\partial y}\right) d x d y, \xi_{i}^{A}=\frac{1}{S_{i}^{A}} \iiint_{A_{i}}\left(\frac{\partial v_{i}}{\partial x}-\frac{\partial u_{i}}{\partial y}\right) d x d y, \quad(i=1,2),
$$


where $C_{i}, A_{i}$ are areas occupied by cyclones and anticyclones respectively; $S_{i}^{C}$, $S_{i}^{A}$ are areas under cyclones and anticyclones; $i$ is number of the layer.

Due to the adhesion conditions on the lateral borders of the total cyclonic and anticyclonic vorticity in the basin are equal in absolute value: $\xi_{i}^{C} S_{i}^{C}+\xi_{i}^{A} S_{i}^{A}=0$. But the area under the anticyclones and cyclones may be different, so the mean values of the cyclonic and anticyclonic vorticity in absolute value are not equal. The values $\xi_{i}^{C}$ and $\xi_{i}^{A}$ can be applied as an integral vorticity field characteristics in the sea.

Fig. 5, $c, f$ show the graphs of $\xi_{1}^{C}, \xi_{2}^{C} \xi_{1}^{A}$ and $\xi_{2}^{A}$, calculated in accordance with the instantaneous current velocity values in B1 and A1 experiments. As it can be seen from the aforementioned figures, in moth cases the mean anticyclonic vorticity in the upper layer is 1.5 times more than the cyclonic one in absolute value. Such pattern is obviously caused by cyclonic wind effect. For the lower layer the same vorticity characteristics are almost equal in absolute value. It is noteworthy that both in experiments respective quantities $\xi_{1}^{C}, \xi_{2}^{C} \xi_{1}^{A}$ and $\xi_{2}^{A}$ take close values unlike energy and tangential wind stress work. This means that in B1 experiment under $\beta>0$ the mean velocity field vorticity, similar by the magnitude in A1 experiment $(\beta=0)$ is achieved at a lower energy level.

In B2 and A2 experiments in order to relieve barotropic component of currents was set $\left(r_{b}=0.1 \mathrm{~cm} / \mathrm{s}\right)$ more by an order of the bottom friction. As a result, in A2 experiment (Fig 6, $a-e$ ) under the constant Coriolis parameter the large-scale circulation separation into individual cyclonic eddies, as in A1 Experiment, did not take place. There was a large cyclonic gyre observed in the sea. It occupied the central part of the basin. On its periphery mesoscale anticyclones periodically arose. They moved along the coast in the direction of the main stream. The areas of anticyclonic vorticity (hydrodynamic instability of currents) were mainly tied to the protruding features of the coastline.

Taking into consideration $\beta$-effect in B2 experiment (Fig. 6, $f-j$ ), in comparison with A2 one, the separate eddy formations began to be more clearly identified in the instantaneous fields, especially in $\psi$ and $u_{2}$ fields (Fig. 6, $i, j$ ). Although in general circulation changed little.

In the mean fields $\psi$ and $h_{1}$ in B2 experiment (Fig. 7) the west intensification of currents is visible and the area of anticyclonic vorticity at the eastern boundary of the basin appeared. In addition, in the averaged field $h_{1}$ the cyclonic circulation in the basin center has two centers ("Knipovich glasses"), which was not observed in $\mathrm{B} 1$ experiment. 

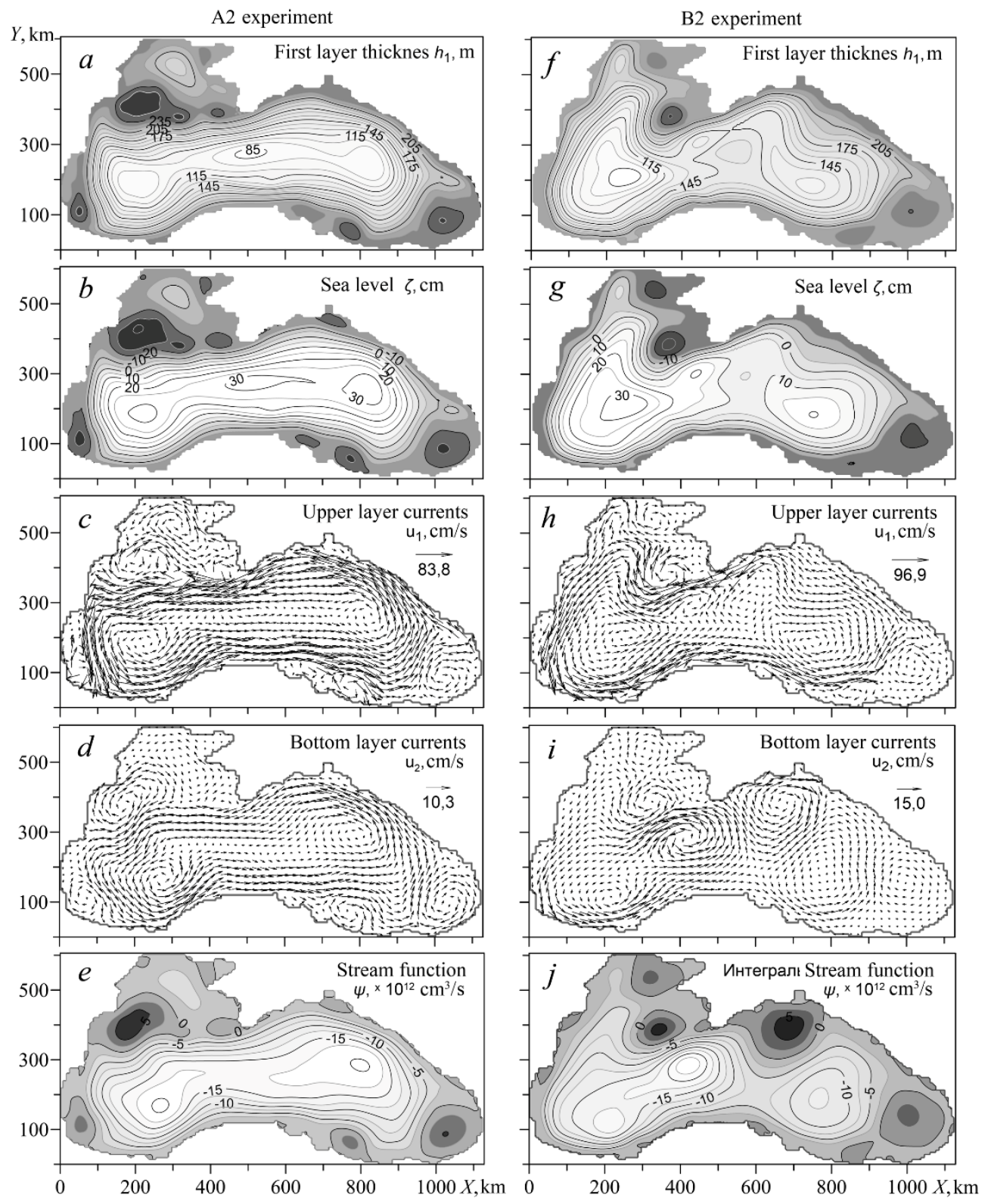

Fig. 6. Instantaneous distributions of the characteristics in A2 (left) and B2 (right) experiments

Like in B1 experiment, the eddy formations represented in the instantaneous fields moved in the western direction. It is well observed on the time diagrams $\psi$ and $h_{1}$, built for the section $Y=270 \mathrm{~km}$ (Fig. 8). In diagram $\psi$ the waves moving from the east to the west with the phase velocity of $7-8 \mathrm{~cm} / \mathrm{s}$ are clearly identified. In the field $h_{1}$ (Fig. 8, $b$ ) the phase velocity of the observed waves is less and equals $\sim 6.5 \mathrm{~cm} / \mathrm{s}$. 


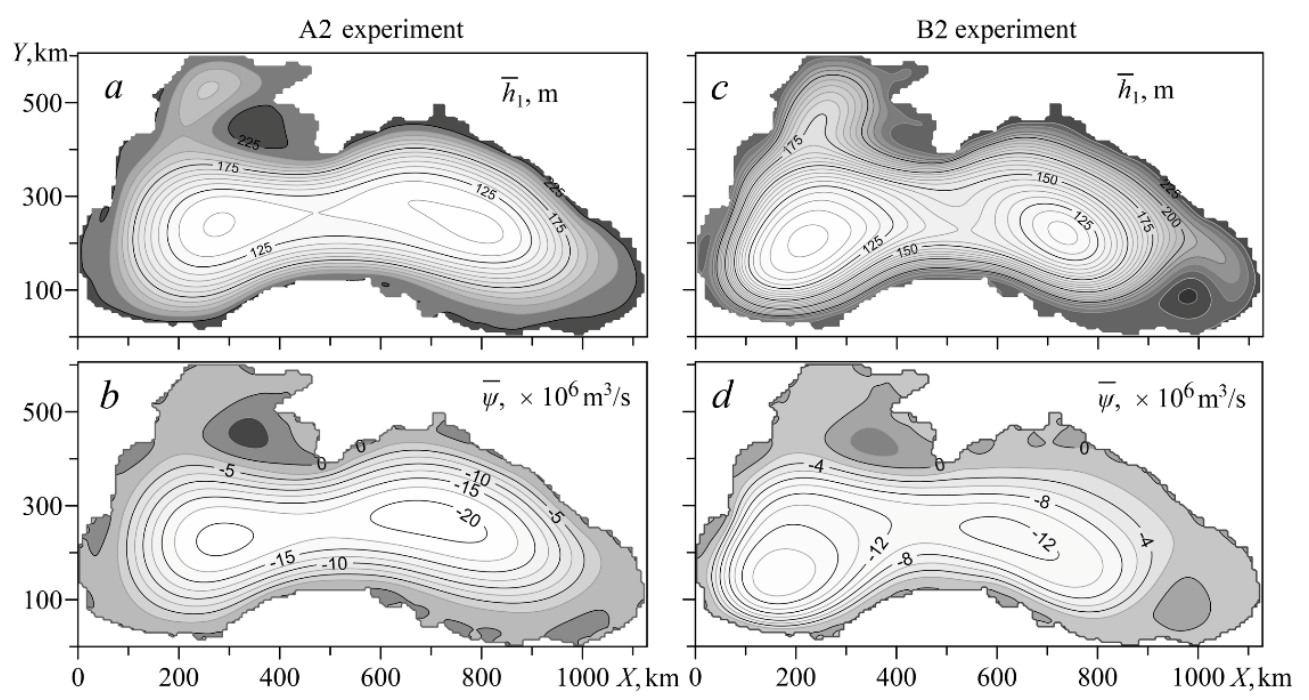

Fig. 7. Mean distributions $h_{1}$ and $\psi$ in A2 (left) and B2 (right) experiments

Fig. 9 shows graphs of $K E_{1}, K E_{2}, D P E, W_{\tau}, \xi_{1}^{C}, \xi_{2}^{C} \xi_{1}^{A}$ and $\xi_{2}^{A}$, plotted for $\mathrm{A} 2$ and $\mathrm{B} 2$ experiments. It is clear that as compared with $\mathrm{A} 1$ and $\mathrm{B} 1$ experiments (Fig. 5, $a, d$ ) the more intense bottom friction leads to a significant decrease of $K E_{2}$ and increase of $D P E$, with practically unchanged $K E_{1}$.

$\beta$-effect in B2 experiment (Fig. 9, a) caused the energy decrease (especially $D P E$ ) comparing with A2 experiment (Fig. 9, $d$ ), at that the vorticity features (Fig. 9, $c, f)$ did not changed significantly.

Summarizing the results of B1 and B2 experiments, we can assume that in the Black Sea under the cyclonic wind influence the role of $\beta$-effect leads to the formation of long-period waves, which are manifested in the form of alternating eddies moving in the western direction. These waves can be most clearly traced in the field $\psi$.

Similar results have already been obtained and are described in the papers [7 9]. In [8] to determine the nature of the observed processes, the authors compared the model results with the normal modes of own vibrations of a rectangular basin with a homogeneous liquid, with the length, width and depth roughly corresponding to the Black Sea parameters.

The solution of the system of equations of natural vibrations in $\beta$-plane for the rectangular two-layer ocean geostrophic approximation is given in [10]. In this case the system of equations has the following form

$$
\begin{aligned}
& \frac{\partial}{\partial t} \Delta \psi_{1}+\beta \frac{\partial \psi_{1}}{\partial x}-E_{1} \frac{\partial}{\partial t}\left(\psi_{1}-\psi_{2}\right)=0, \\
& \frac{\partial}{\partial t} \Delta \psi_{2}+\beta \frac{\partial \psi_{2}}{\partial x}-E_{2} \frac{\partial}{\partial t}\left(\psi_{2}-\gamma \psi_{1}\right)=0,
\end{aligned}
$$

where $\psi_{1}, \psi_{2}$ are stream functions, for vertically averaged velocities in the upper and lower layer; $E_{1}=f^{2} /\left(g h_{1} \varepsilon\right) ; E_{2}=f^{2} /\left(g h_{2} \varepsilon\right) ; \varepsilon=\left(\rho_{2}-\rho_{1}\right) / \rho_{2} ; \gamma=\rho_{1} / \rho_{2}$ 


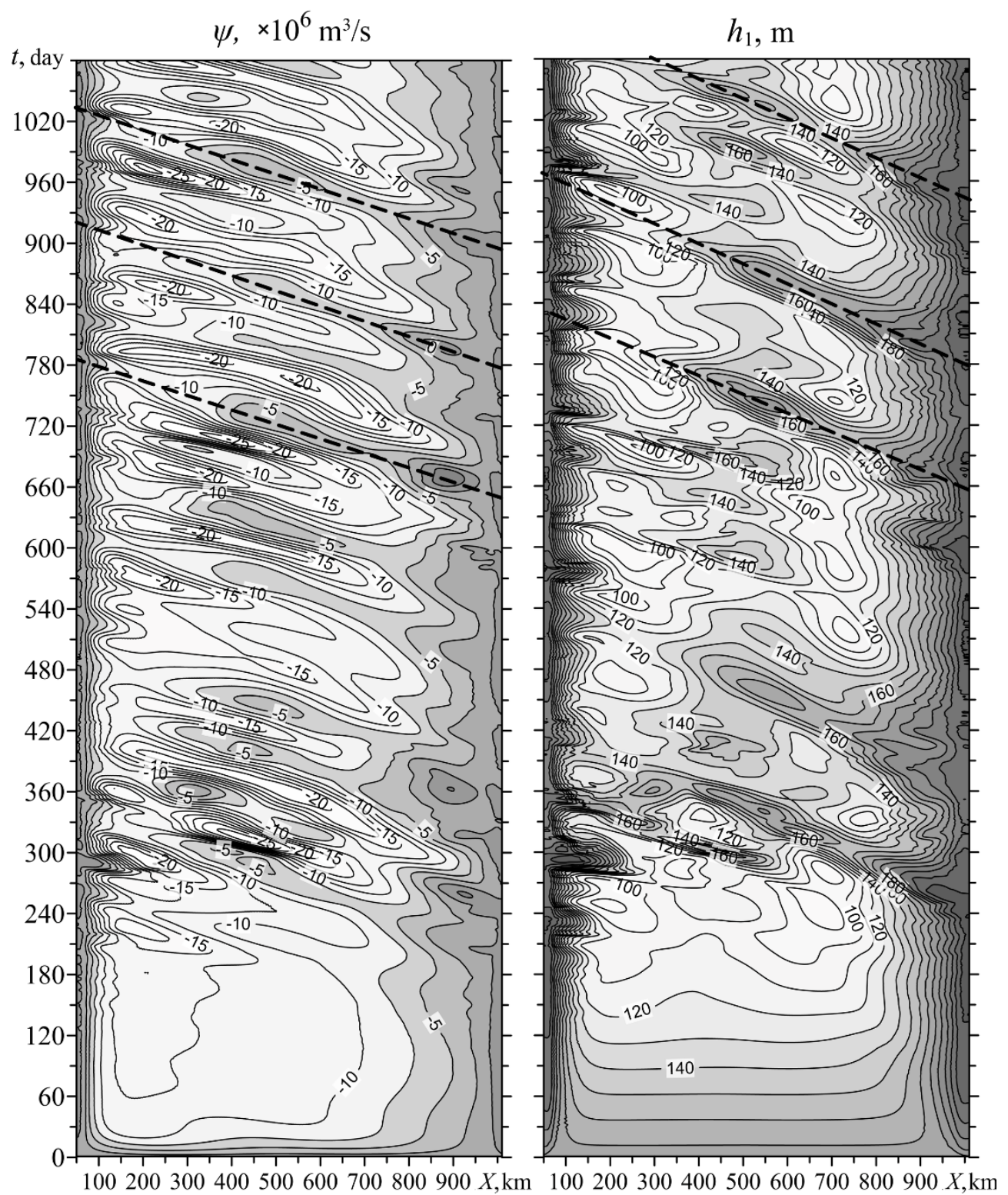

Fig. 8. Time diagrams $\psi$ (left) and $h_{1}$ (right) on the section $Y=270 \mathrm{~mm}$ in B2 experiment 

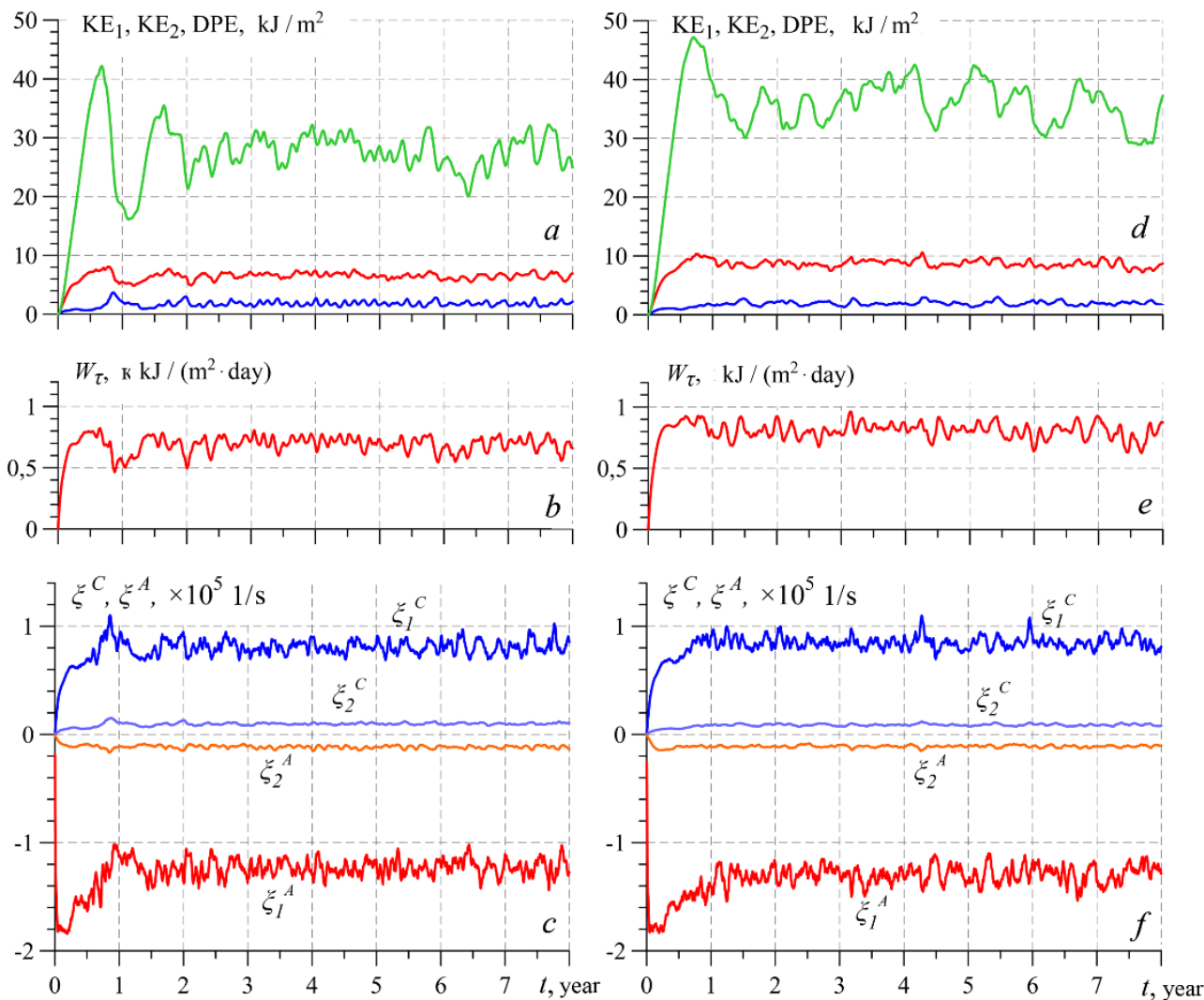

Fig. 9. Graphs of the $K E_{1}, K E_{2}$ and $D P E$ energy in $\mathrm{B} 2-a$ and $\mathrm{A} 2-d$ experiments; tangential wind stress work $W_{\tau}$ in $\mathrm{B} 2-b$ and $\mathrm{A} 2-e$ experiments; mean vorticity in B2 $-c$ and $\mathrm{A} 2-f$ experiments

Multiplying the second equation of the system (2) by an arbitrary constant $\alpha$, and adding it to the first one, we obtain the following

$$
\frac{\partial}{\partial t} \Delta\left(\psi_{1}+\alpha \psi_{2}\right)+\beta \frac{\partial}{\partial x}\left(\psi_{1}+\alpha \psi_{2}\right)-E_{1} \frac{\partial}{\partial t}\left[\psi_{1}\left(1-\alpha \alpha_{0} \gamma\right)+\psi_{2}\left(\alpha \alpha_{0}-1\right)\right]=0,
$$

where $\alpha_{0}=h_{1} / h_{2}$.

Then we are to define a new dependent variable $F$ and an arbitrary constant G:

$$
F=\psi_{1}+\alpha \psi_{2}=\left[\psi_{1}\left(1-\alpha \alpha_{0} \gamma\right)+\psi_{2}\left(\alpha \alpha_{0}-1\right)\right] G,
$$

as a result we obtain the following equation of the normal vibrations

$$
\frac{\partial}{\partial t} \Delta F+\beta \frac{\partial F}{\partial x}-\frac{E_{1}}{G} \frac{\partial F}{\partial t}=0 .
$$

From (3) we can find the values of the arbitrary constants $\alpha$ and G: 


$$
G=\frac{1}{1-\alpha \alpha_{0} \gamma}, \quad \alpha=\frac{\alpha \alpha_{0}-1}{1-\alpha \alpha_{0} \gamma} .
$$

To determine $\alpha$ we obtain a quadratic equation as follows

$$
\alpha^{2}+\frac{\alpha_{0}-1}{2 \alpha_{0} \gamma} \alpha-\frac{1}{\alpha_{0} \gamma}=0
$$

from which we find

$$
\alpha_{1,2}=-\frac{\alpha_{0}-1}{2 \alpha_{0} \gamma} \mp \sqrt{\frac{\left(\alpha_{0}-1\right)^{2}+4 \alpha_{0} \gamma}{4 \alpha_{0}^{2} \gamma^{2}}} .
$$

Taking into account $F_{i}=\psi_{1}+\alpha_{i} \psi_{2}(i=1,2)$ the equation (5) is rewritten in the following way:

$$
\frac{\partial}{\partial t}\left(\Delta-\frac{E_{1}}{G_{i}}\right) F_{i}+\beta \frac{\partial F_{i}}{\partial x}=0 .
$$

The expression (8) is a well-known equation of planetary waves [15]. It defines two normal fluctuations (barotropic and baroclinic modes) with frequencies $\sigma_{i}$ in a rectangular basin with the $a \times b$ dimensions at $\mathrm{Fi}=0$ on the boundary expressed by the formula below

$$
\sigma_{i}=\frac{\beta}{2}\left(\frac{m^{2} \pi^{2}}{a^{2}}+\frac{n^{2} \pi^{2}}{b^{2}}+\frac{E_{1}}{G_{i}}\right)^{-1 / 2},
$$

where $i=1,2$; $m$ and $n$ are whole numbers.

Taking into account (6) and (7), two values for $E_{1} / G_{i}$ can be found:

$$
\frac{E_{1}}{G_{1}}=\frac{f^{2}}{g\left(h_{1}+h_{2}\right)}, \quad \frac{E_{1}}{G_{2}}=\frac{f^{2}\left(h_{1}+h_{2}\right)}{g \varepsilon h_{1} h_{2}} .
$$

The first expression defines a value for the barotropic oscillation mode with an equivalent depth of $H=h_{1}+h_{2}$, the second one - for the baroclinic modes with equivalent depth of $H=\varepsilon \frac{h_{1} h_{2}}{\left(h_{1}+h_{2}\right)}$.

Solution of the equation (8) for a rectangular basin with the $a \times b$ dimensions under $F_{i}=0$ on a solid boundary was first obtained by Longuet-Higgins [15] and has the following form

$$
F_{i}=\sin \left(\frac{m \pi}{a} x\right) \sin \left(\frac{n \pi}{b} y\right) \cos \left(\gamma_{i} x+\sigma_{i} t\right),(i=1,2)
$$

where $x$ and $y$ are coordinates; $m$ and $n$ are whole numbers; $\gamma_{i}=\frac{\beta}{2 \sigma_{i}}$.

The expression (2) describes the Rossby waves, which are the normal modes of natural oscillations in the basin [6,7]. Under $i=1$ the barotropic mode is 18

PHYSICAL OCEANOGRAPHY NO. 5 (2016) 
obtained, under $i=2-$ the baroclinic one. The phase velocity of the wave $c_{i}=-\sigma_{i} \gamma_{i}^{-1}$, the distance between the moving nodes (half wavelength) $\lambda_{i}=2 \pi \sigma_{i} \beta^{-1}$ and the wave period $T_{i}=2 \pi / c_{i}$.

For the rectangular basin with the dimensions of $1125 \times 285 \mathrm{~km}$ and the depth $H=2200 \mathrm{~m}$, with two water layers having the parameters, analogical to the experiments considered, for the principal $(m=1, n=1)$ barotropic normal mode we obtain: $c_{1}=-7.7 \mathrm{~cm} / \mathrm{s}, \lambda_{1}=276 \mathrm{~km}, T_{1}=82.8$ days, for the principal baroclinic mode: $c_{1}=-0.5 \mathrm{~cm} / \mathrm{s}, \lambda_{1}=69 \mathrm{~km}, T_{1}=331$ days. The wave, related to the main barotropic normal mode has maximum phase velocity. Baroclinic normal modes under the same values of $m$ and $n$ are have smaller phase velocities and wavelengths, than the barotropic modes.

In B1 and B2 experiments, phase velocities of the observed waves (Fig. 4, 8) were obtained close enough to the above calculated velocity of the main barotropic modes of natural oscillations in a rectangular basin. But such a comparison may not look correct due to the strong differences in the shapes of the compared basins. In addition, the calculations using the same formula (10) with different sizes of a rectangular basin showed that the basin width $b$ (the size according to the $Y$-axis) has the greatest effect on the results, and in case of a real configuration it is very difficult to determine the equivalent width of the sea. Therefore additional B3 experiment was carried out in an elongated basin with constant width and boundaries rounded off to the east and west (Fig. 10). As shown in [2], this form allows you to minimize the nonlinearity effect associated with the basin asymmetry and the coastline roughness. The length, width and depth matched the dimensions of the rectangular basin, the normal modes were calculated for. In addition, to compare and control A3 experiment was carried out, which differs from B3 one by zero value of $\beta$-parameter.

Instantaneous distributions $h_{1}$ and $\psi$, obtained after the problem entrance in the statistical equilibrium mode in B3 and A3 experiments and giving an idea of the circulation in the upper and lower layer, are shown in Fig. 10, $a, b, d$ and $e$. Distributions of the other characteristics are not presented, as there is a good crosscorrelation between fields $h_{1}, \zeta, \vec{u}_{1}$ and $\psi, \vec{u}_{2}$, as well as in the previously considered pairs of the experiments. As it can be seen in Fig. 10, $a-d$, in A3 experiment the large-scale circulation was divided into three rounded shape cyclones with a diameter equal to the basin width. Two zones are located between the cyclones. There are mesoscale anticyclonic eddies periodically encountered (Fig. $10 a, b$ ). In the averaged field $h_{1}$ (Fig. 10, c, d) cyclonic circulations are only observed. Some anticyclonic eddies are not expressed because of their unsteadiness. In $\psi$ field (Fig. $10, d)$ two anticyclonic vorticity areas are observed between the three stationary cyclones.

A3 experiment peculiar feature is the presence of the central symmetry in the spatial distribution of all the characteristics - the instantaneous and averaged ones. In B3 experiment taking into account $\beta$-effect the circulation separation in the individual eddies takes place (Fig. $10 d, e$ ), but there is no symmetry of the fields. In the medium fields $h_{1}$ and $\psi$ (Fig. 10, $f, h$ ) the separate eddy structures observed 
in the instantaneous fields, are not manifested. A slight thickening of the contour as a result of the intensification of western currents is observed near the western coast.
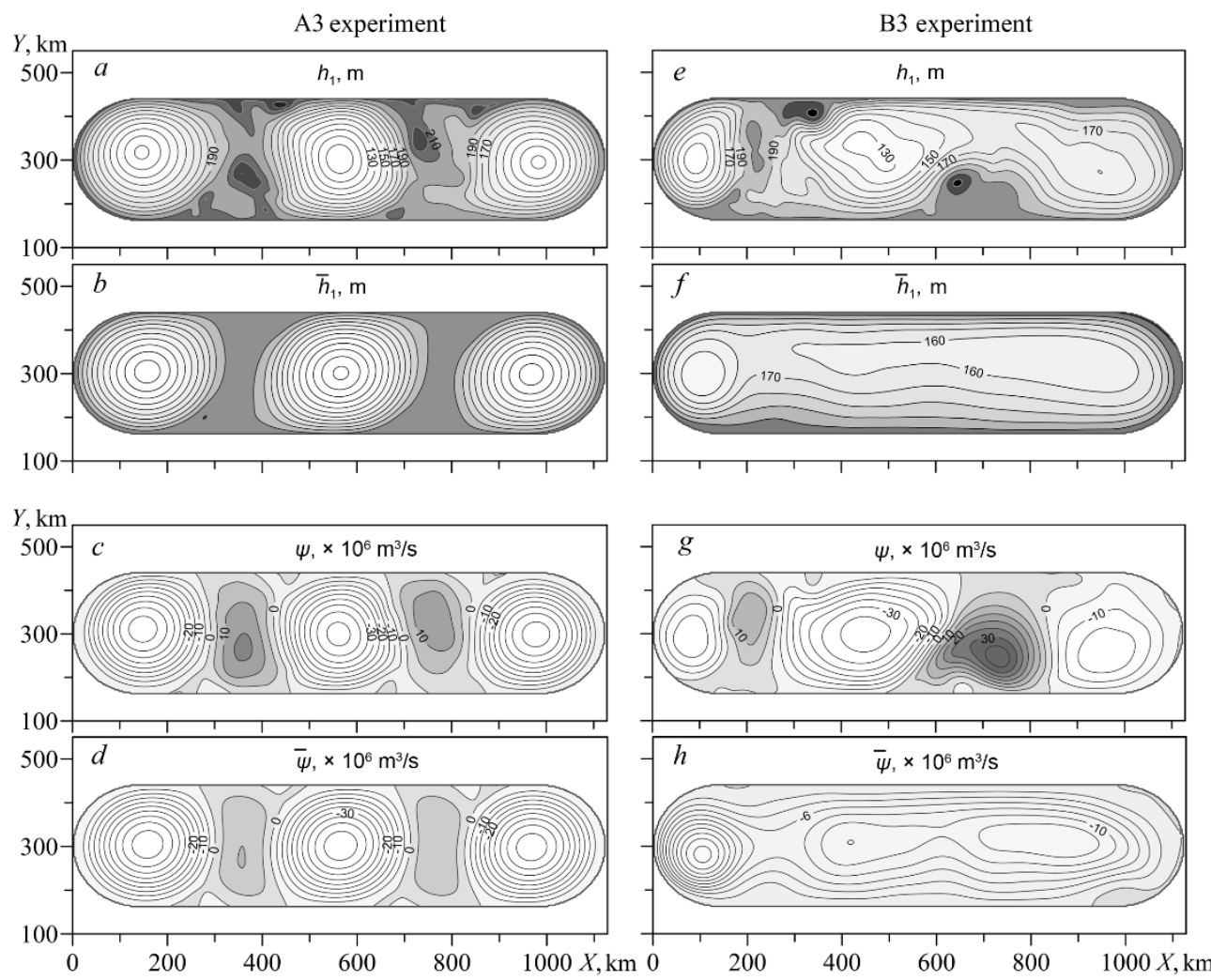

Fig. 10. Instantaneous and mean fields in $\mathrm{A} 3$ experiment: $h_{1}-a ; \bar{h}_{1}-\mathrm{b} ; \psi-c ; \bar{\psi}-d$, Instantaneous and mean fields in B3 experiment: $h_{1}-e ; \bar{h}_{1}-f ; \psi-g ; \bar{\psi}-h$

In B3 experiment all the eddy formations move in the western direction. This is clearly shown in Fig. 11 (left). There the successive fields $\psi$, built in the period of 15 days, are demonstrated. If they are compared with the main barotropic normal mode distribution, calculated with the same frequency (Fig. 11, right), great similarity will be found. Also, time diagrams $\psi$ and $h_{1}$, built for the latitudinal section passing through the central axis of the basin (Fig. 12), are in a very good agreement with the barotropic normal mode. All the diagrams clearly show wave with a period of 90 days, moving in the western direction with the phase velocity of $7.5 \mathrm{~cm} / \mathrm{s}$. Thus, it is possible to make presumptive conclusion that by accounting for the influence of $\beta$-effect in B1, B2 and B3 numerical experiments the Rossby waves were obtained. They correspond to the normal barotropic modes of natural oscillations in a closed basin. These waves can be best seen in the field $\psi$, which characterizes the barotropic component of currents. In diagram $h_{1}$ (Fig. 12, c) you can see traces of the movement of mesoscale anticyclonic eddies on the barotropic 
Rossby wave background in the areas of positive values of $\psi$, which correspond to anticyclones.
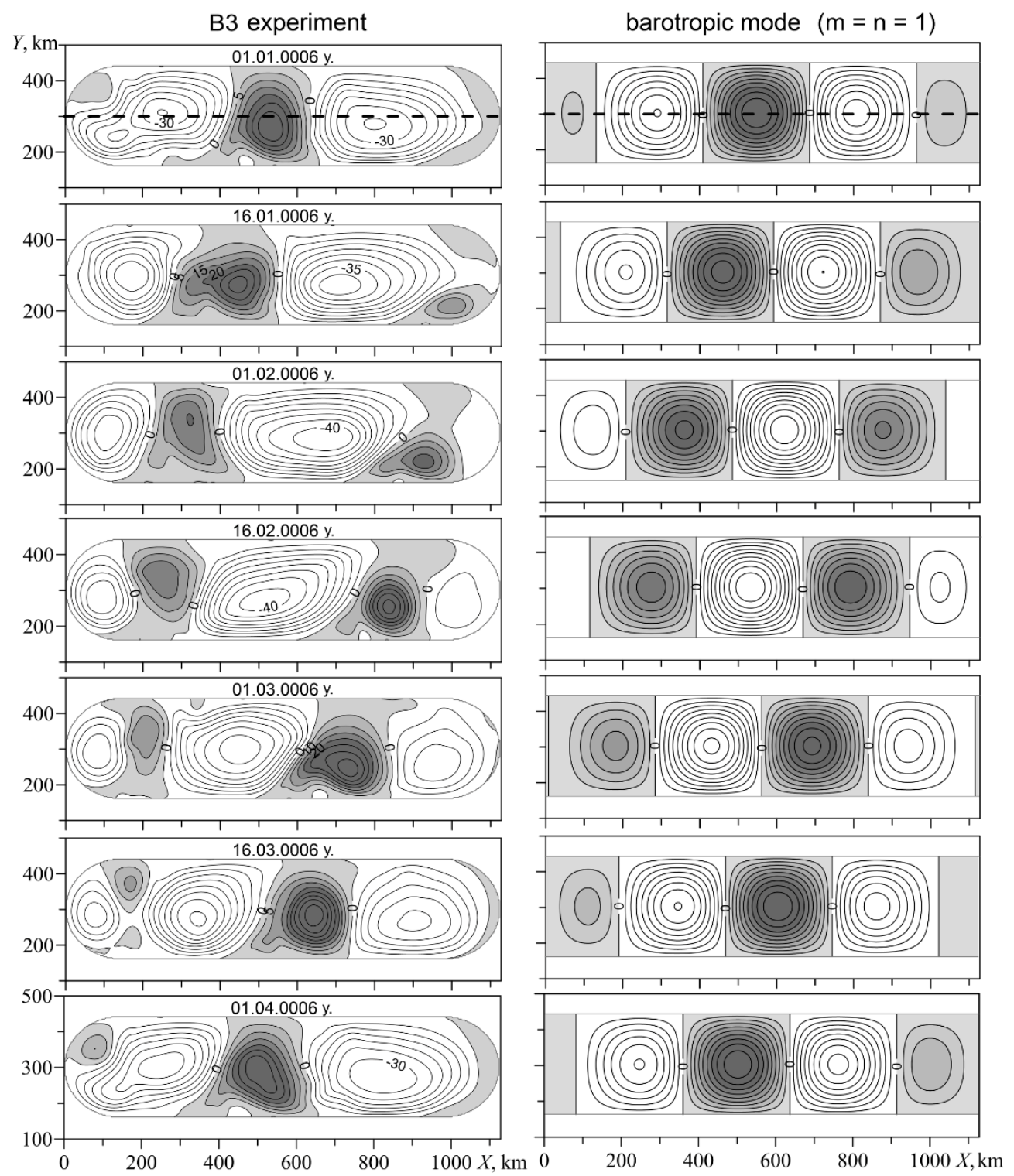

Fig. 11. Consistent spatial distributions $\psi$ with the period of 15 days in B3 experiment (left) and normal mode in a rectangular basin with $m=n=1$ (right). The dotted line indicates the latitudinal sections along the central axis of the basins 

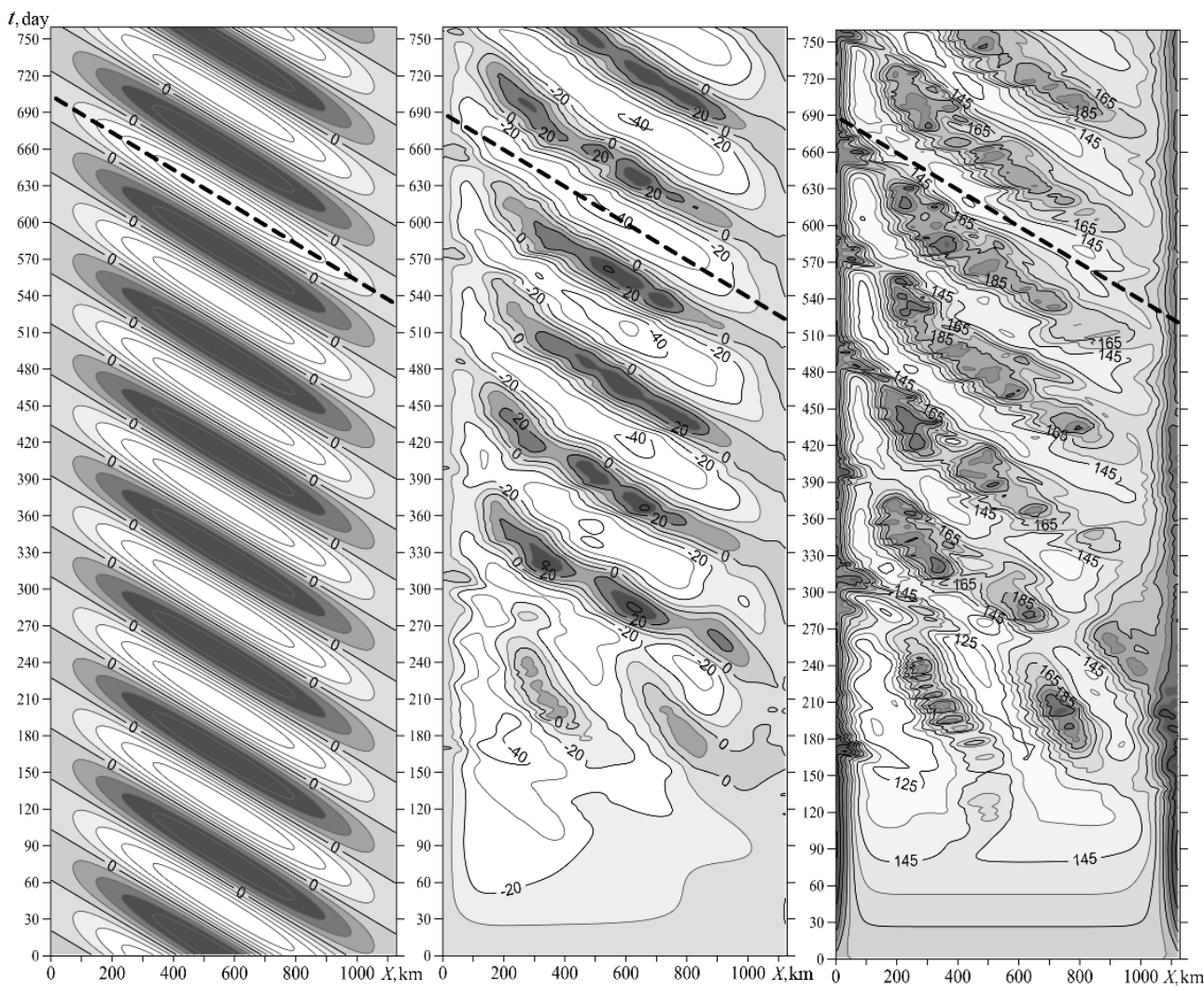

Fig. 12. Consistent spatial distributions at the latitudinal sections along the central axis of the basin for $\psi$, corresponding to the normal mode (left) in B3 experiment (center), $h_{1}$ in B3 experiment (right)

As for the Rossby waves caused by baroclinic modes of the normal vibrations, which, according to theory, should also be present in the solution, they were failed to be identify explicitly in the considered experiments. Most likely, this is due to the fact that the self-oscillating process, changing the sink of energy from the wind and resulting in the oscillation of the observed waves, has the frequency the barotropic Rossby waves predominantly occur at. Theoretical ocean response research on the different types of external exposure is considered in [14]. It is shown that the external effect at the intervals of several weeks - months mostly results in the barotropic Rossby waves. But for the baroclinic waves to appear the oscillating force frequency should be more than a year.

Conclusions. A good match of features of the waves, obtained in the experiment, with the analytic solution of the planetary wave equation gives reason to believe that in the study area there are Rossby waves corresponding to the main normal barotropic mode of the natural basin oscillations. Under steady external effect the initial velocity field oscillations are due to hydrodynamic instability of currents and are further supported by the self-oscillating process that regulates energy sink into the sea by the wind. The amplitude of Rossby wave baroclinic mode was small compared with the amplitude of the barotropic mode, and was difficult to distinguish in the obtained fields. 
Analysis of the behavior of energy characteristics showed that the $\beta$-effect reduces the tangential wind stress work, which in its turn determines the lower level of the energy components calculated in the model. Rossby waves have a stimulating effect on the processes of hydrodynamic instabilities that lead to the appearance of opposite wind vorticity mesoscale eddies.

On the basis of the performed experiments we can agree with the conclusion of the authors of the article [8] that the $\beta$-effect and associated Rossby waves in the Black Sea can have a significant impact on the formation of large-scale circulation, comparable to the baroclinic instability effect.

\section{REFERENCES}

1. Pavlushin, A.A., Shapiro, N.B., Mikhaylova, E.N. \& Korotaev, G.K., 2015, “Two-layer eddyresolving model of wind currents in the Black Sea”, Physical oceanography, no. 5, pp. 3-12.

2. Pavlushin, A.A., Shapiro, N.B., Mikhaylova, E.N, 2016, "Effect of the basin shape on formation of the Black Sea circulation”, Physical oceanography, no. 2, pp. 3-15.

3. Seidov, D.G., 1989, "Sinergetika okeanskikh protsessov [Synergetics of the ocean processes]”, Leningrad, Gidrometeoizdat, 288 p. (in Russian).

4. Gill, A., 1986, "Dinamika atmosfery i okeana. T. 1 [Atmosphere and ocean dynamics. Vol. 1]”, Moscow, Mir, 396 p. (in Russian).

5. $\quad$ Kamenkovich, V.M., Monin, A.S., 1978, "Fizika okeana. T. 2-Gidrodinamika okeana [Ocean physics. T2-Ocean hydrodynamics]”, Moscow, Nauka, 435 p. (in Russian).

6. Kamenkovich, V.M, Koshlyakov, M.N. \& Monin, A.S., 1987, "Sinopticheskie vikhri v okeane [Synoptical eddies in the ocean]”, Leningrad, Gidrometeoizdat, 510 p. (in Russian).

7. Rachev, N.H., Stanev, E.V., 1997, "Eddy processes in semi-enclosed seas: A case study for the Black Sea”, J. Phys. Oceanogr., no. 27, pp. 1581-1601.

8. Stanev, E.V., Rachev, N.H., 1999, "Numerical study on the planetary Rossby waves in the Black Sea”, J. Mar. Sys., no. 21, pp. 283-306.

9. Demyshev, S.G., Korotaev, G.K. \& Kuftarkov, A.Yu., 1996, “Analiz nachal'nogo perioda prisposobleniya geofizicheskikh poley Chernogo morya $k$ novoy chislennoy modeli [Analysis of the initial adaptation period of the Black Sea geophysical fields to the new numerical model]”, Izv. RAN. FAO, vol. 32, no. 5, pp. 635-644 (in Russian).

10. Korotaev, G.K., Saenko, O.A. \& Koblinsky, C.J., 2001, "Satellite altimetry observation of the Black Sea level”, J. Geophys. Res., iss. 106, no. C1, pp. 911-933.

11. Blatov, A.S., Bulgakov, N.P. \& Ivanov, V.F. [et al.], 1984, "Izmenchivost' gidrofizicheskikh poley Chernogo morya [Variability of hydrophysical fields of the Black Sea]”, Leningrad, Gidrometeoizdat, 239 p. (in Russian).

12. Latun, V.S., 1989, “Antitsiklonicheskie vikhri v Chernom more letom 1984 goda”, Morskoy gidrofizicheskiy zhurnal, no. 3, pp. 27-34 (in Russian).

13. Latun, V.S., 1990, "Energosnabzhenie glubokikh antitsiklonicheskikh vikhrey Chernogo morya [Power supply of the Black Sea deep anticyclonic eddies. Complex oceanographic research of the Black Sea: Proceedings]”, Kompleksnye okeanograficheskie issledovaniya Chernogo morya: Sb. nauch. tr., pp. 10-21 (in Russian).

14. Safronov, G.F., 1985, "Vozbuzhdenie dlinnykh voln $v$ okeane krupnomasshtabnymi izmeneniyami $v$ pole kasatel'nogo napryazheniya vetra [Oscillation of long waves in the ocean by large-scale changes in the tangential wind stress]”, Moscow, Gidrometeoizdat, 108 p. (in Russian).

15. Longuet-Higgins, M.S., 1965, "Planetary waves on a rotating sphere II", Proc. Roy. Soc. A., vol. 284, iss. 1396, pp. 40-68. 